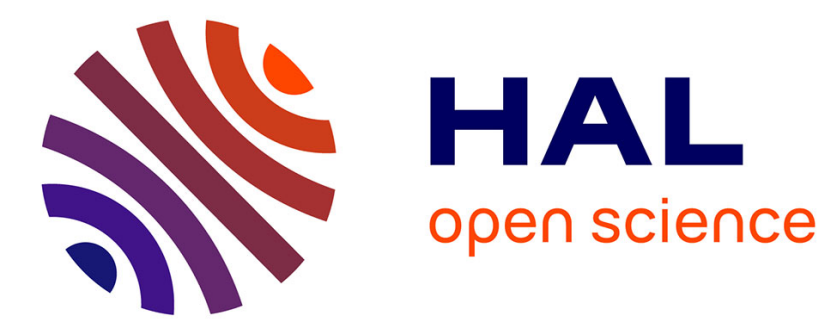

\title{
A glassy model for random lasers
}

Luca Angelani, Claudio Conti, Giancarlo Ruocco, Francesco Zamponi

\section{To cite this version:}

Luca Angelani, Claudio Conti, Giancarlo Ruocco, Francesco Zamponi. A glassy model for random lasers. Philosophical Magazine, 2007, 87 (3-5), pp.587-592. 10.1080/14786430600865364. hal00513732

\section{HAL Id: hal-00513732 \\ https://hal.science/hal-00513732}

Submitted on 1 Sep 2010

HAL is a multi-disciplinary open access archive for the deposit and dissemination of scientific research documents, whether they are published or not. The documents may come from teaching and research institutions in France or abroad, or from public or private research centers.
L'archive ouverte pluridisciplinaire HAL, est destinée au dépôt et à la diffusion de documents scientifiques de niveau recherche, publiés ou non, émanant des établissements d'enseignement et de recherche français ou étrangers, des laboratoires publics ou privés. 


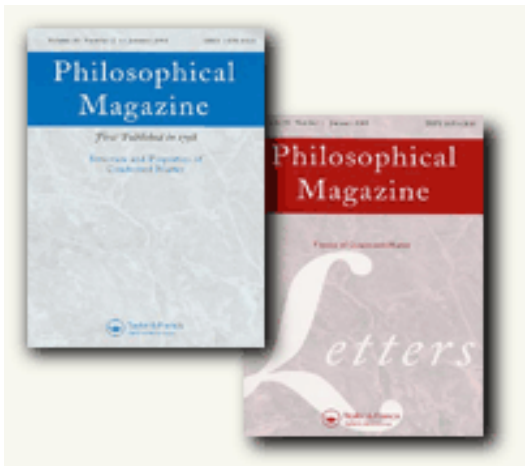

A glassy model for random lasers

\begin{tabular}{|r|l|}
\hline Journal: & Philosophical Magazine \& Philosophical Magazine Letters \\
\hline Manuscript ID: & TPHM-06-May-0152.R1 \\
\hline Journal Selection: & Philosophical Magazine \\
\hline Author: & 31-May-2006 \\
\hline Complete List of Authors: & $\begin{array}{l}\text { Angelani, Luca; Research center SMC INFM-CNR c/o Dip. Fisica } \\
\text { Univ. La Sapienza Roma } \\
\text { Conti, Claudio; Centro studi e ricerche "Enrico Fermi", Roma } \\
\text { Ruocco, Giancarlo; Univ. of Rome, Physics } \\
\text { Zamponi, Francesco; LPTENS }\end{array}$ \\
\hline Keywords: & disordered systems, glass transition, lasers \\
\hline Keywords (user supplied): & \\
\hline $\begin{array}{l}\text { Note: The following files were submitted by the author for peer review, but cannot be converted } \\
\text { to PDF. You must view these files (e.g. movies) online. }\end{array}$ \\
\hline \begin{tabular}{l} 
paper.tex \\
\hline
\end{tabular}
\end{tabular}

\section{S) ScholaroNE \\ Manuscript Central}




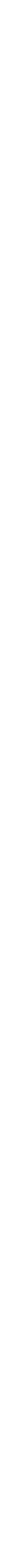

